\title{
A review of methods for highway-railway crossings safety management process
}

\section{Behzad Dezhkam¹, Seyed Mehrdad Eslami}

${ }^{1}$ Faculty member of Civil Engineering University of velayat,Iranshahr, Iran. ${ }^{2}$ Faculty member of engineering department, Velayat university, Iranshahr, Iran

\section{ABSTRACT}

This paper reviews the literature concerning the risks associated with Highway- Railway Crossings (HRC). The aim of this study is to evaluate and validate previous investigations conducted in the United States and Canada. The main issues addressed in this paper are: a) Identify HRC with potential the average collision frequency or collision severity as black spots, tests that are used to identifying hazardous location and compare the methods, b)Identify the contributing factors to safety problems at an identified HRC location, c)Identification of countermeasures to address the contributing factors. This research has thrown up many questions in need of further investigations on risks associated with HRC to mitigate the accident frequency and injury severity.

KEYWORDS

Highway-railway crossings safety management process

\section{ARTICLE HISTORY}

Received 15 September 2016

Revised 10 November 2016

Accepted 22 February 2017

\section{Introduction}

Safety is a major public concern in our daily life. Annually, a lot of people lost their lives due to road accident. Among the various types of road accident, accidents between trains and road vehicles are the strongest and most expensive accidents.

In order to improve safety, there is a standard procedure for identifying and eliminating hazardous locations consists of the following six general steps:

1. Identifying high-hazard locations based on reported crash data.

2. Identify the contributing factors to safety problems at an identified hazardous location

3. Identifying possible countermeasures for hazardous locations.

4. Predicting the effect of potential countermeasures in terms of reduced numbers of crashes or severity of crashes.

5. Implementing countermeasures with the highest net benefits on investment.

6. Evaluating the effectiveness of the countermeasures after implementation.

\section{CORRESPONDENCE Behzad Dezhkam}

\section{(c) 2017 Dezhkam \& Eslami}

Open Access terms of the Creative Commons Attribution 4.0 International License apply. The license permits unrestricted use, distribution, and reproduction in any medium, on the condition that users give exact credit to the original author(s) and the source, provide a link to the Creative Commons license, and indicate if they made any changes. (http://creativecommons.org/licenses/by/4.0/) 
Using these six steps, safety can be increased to the desired location. The first three of these steps, hotspot sites identification, characterization and identification of site factors and selection countermeasure is performed. In this paper, we focus to these steps and review the literature. In step one; we investigate the network screening method that used for road and rail network. The intersection of two different modes of transportation presents a set of unique safety concern so one of these hazardous locations is highway-railway grade crossing, that today, these points accounted for a high percentage of accidents in North America. Table 1 shows the number of crossing and accidents in USA and Canada at 2011 (Transportation Safety Board of Canada, 2011).

Table 1: number of crossing and accidents in USA and Canada at 2011

\begin{tabular}{|c|c|c|c|c|}
\hline Country & Number of crossing & Accident & Fatalities & Injuries \\
\hline USA & 248273 & 1967 & 265 & 989 \\
\hline Canada & 37000 & 169 & 25 & 51 \\
\hline
\end{tabular}

So, in next step, presented factors of this site in literature is review. The last step of this paper, crossing countermeasures is surveyed. It should be noted that because of the high number of crossing and accidents, this paper is focused in North America for study.

The remainder of the paper is organized as follows. Previous research works in network screening methods is reviewed in next section. In next sections factors and countermeasures of crossing is investigated. Finally, in last section concludes the findings.

\section{Network screening}

Network screening (NS) is the first step in the site safety improvement process. The objective of NS is to identify transportation system locations that possess underlying correctable safety problems, and whose effect will be revealed through elevated crash frequencies relative to similar locations. The product of network screening is a list of sites that are ranked by priority for the conduct of detailed engineering studies. There is variety of methods for NS, particularly to identify areas of risk in the road network. In this section of the paper, the presented methods of NS in road and rail networks in North America are explained.

From previous research, (Persaud and Hauer, 1984, Persaud, 1986, 1988 and Hauer, 1997) can be noted that has shown that methods relying on a simple ranking of crash counts leading to the attempted remediation of safety problems at relatively safe locations. Hauer and Persaud (1984) drew an analogy between the first stage of identification of black spots, and discussed how to measure the performances of various methods of identifying hotspot sites. On the basis of this study, Higle and Hecht (1989) conducted a simulation experiment to evaluate and compare techniques for the identification of hazardous locations in terms of crash rates. Maher and Mountain (1988) also use a simulation-based approach to compare methods, including ranking of sites on the basis of annual accident totals and potential accident reduction.

Highway agencies use different NS methods. The NS methods most commonly used in practice are the ranking of crash frequency (CF) and the ranking of crash rate (CR) (Persaud, 2001; PIARC, 2004; TAC, 2004). To take crash costs into account, the equivalent property damage only (EPDO) crash frequency method is sometimes used (PIARC, 2004; TAC, 2004). Based on the assumption that only excess crashes over those expected from similar sites can be prevented by applying appropriate treatments, the potential for improvement, measured as the difference between the observed (or estimated with the empirical Bayes (EB) method) and the expected crash frequency, is also used as an NS method (Austroads, 2009; El-Basyouny and Sayed, 2006; Persaud et al., 1999; PIARC, 2004; ROSPA, 2002). Since the existence of crash patterns susceptible to correction may be accompanied by an overrepresentation of crash frequency (Kononov, 2002), the proportion method is sometimes used; this method prioritizes sites according to the probability that the observed proportion of a crash type at a site is truly above a given critical proportion (Lyon et al., 2007; PIARC, 2004). Crash count does not always give an unbiased estimate of the long-term expected number of crashes, because crash counts can 
randomly fluctuate during the observation period. This observation has generated interest in techniques that control for random fluctuations in the recorded number of crashes; the empirical Bayes (EB) technique is one example (Hauer, 1997; Hauer et al., 2002; Persaud and Lyon, 2007). Another method that a large used for identification of hotspot is binomial and beta-binomial (BB) test. Many studies (Bahar et al., 2007; Bolduc and Bonin, 1995; Heydecker and Wu, 1991; Kononov, 2002; Kononov and Allery, 2004; Kononov and Janson, 2002; Lyon et al., 2007; Masliah and Bahar, 2006; Masliah et al., 2006; Montella, 2010; Park and Sahaji, 2012; Sayed et al., 1997) have applied the binomial test and/or the BB test to screen various roadway networks in different jurisdictions, and have showed acceptable levels of success. Heydecker and Wu (1991) introduced the BB test in the area of road safety. They called the approach the "two stage model of proportions." Since then, a number of researchers have applied the BB test. The California Department of Transportation (Caltrans) uses Table $\mathrm{C}$ and related documents to identify and to investigate locations within the state highway system where a relatively large number of collisions occur.

Recently, Stokes and Mutabazi (2012) presented a rate-quality control method and Duckworth et al. (2011) developed a combining two common screening methods: critical collision rate and weighted severity in highway.

The studies on the rail network can be noted to the report that presented a risk-based model for identifying highway-railway grade crossing black spots in Canada (Saccomanno et al. 2003, 2004). In this report consists of two prediction components: 1) collision frequency and 2) collision consequence and Poisson and Negative Binomial (NB) frequency prediction expressions were developed for crossings. Typical absolute collision prediction models were developed by Coleman and Stewart (1976) and the U.S. Department of Transportation (USDOT) (1987). The USDOT model is generally recognized as being the industry standard for collision risk prediction at highway-rail grade crossings.

Compared with the large number of studies focused on the development of various NS methods, considerably less research has been dedicated to comparing the performance of various methods (Cheng and Washington, 2005). Central to the comparison of NS methods is the identification and development of robust and informative quantitative and qualitative criteria that can be used to evaluate the methods. Like the selection of statistical and econometric models, numerous assessment criteria are needed to assess NS methods. Cheng and Washington (2008) proposed the use of five (four new) quantitative evaluation tests aimed at comparing alternative NS methods. These five tests evaluate a variety of aspects of each NS method's performance. The site consistency test measures each method's efficiency in identifying sites that show consistently poor safety performance. Persaud et al. (1999) compared the crash frequency method, the crash rate method, the PFI method, and the EB method; they used both the crash frequency and the difference between observed and predicted crashes in a subsequent time period as measures of effectiveness.

Most important methods that used to be compared are four quantitative evaluation tests: the site consistency test, the method consistency test, the total rank differences test, and the total score test (Chengand Washington, 2008). Furthermore these factors will be discussed:

1. Site consistency test or the method consistency test measures the ability of an NS method to consistently identify a high-risk site over repeated observation periods.

2. The method consistency test evaluates a method's performance by measuring the number of the same hotspots identified in both time periods.

3. Total rank differences test calculate the sum of the total rank differences of the hotspots identified across the two periods.

4. Total score test combines the site consistency test, the method consistency test, and the total rank difference test in order to provide a synthetic index.

At the end and according to conducted surveys, comparisons of models are presented.

- The EB method performs better than the other (most consistent and reliable). EB was better than EBs.

- $\quad$ The CF method performed better than the CR method

- $\quad$ The PFI and EPDO were largely inconsistent.

- The proportion method performed worst in all of the tests. 


\section{Factors}

There are factors that cause a site to be identified as a black spot. Risk factors refer to crossing attributes that explain variation in risk including the expected number of collisions and their consequences. In this analysis we consider the four types of risk- factors: rail, road, environmental and human factor:

Rail factors: The main railway characteristics that affect risk at grade crossings include condition of the tracks, railway geometric data, track angle, train speed, train conspicuity, number of railway lines, number of trains per day, railroad traffic volume. (Transportation development center of Canada, 2000; Caros, 2005; Multer et al. 2012; Miranda-Moreno et al, 2009)

Road factors: Factors such as condition of the roadway, highway geometric data, area type, position of signs, type of vehicle, control device length, guardrail height, guardrail length, type of roads, number of lanes, road surface type and width, illumination, conditions of the pavement, road traffic volume, transit of pedestrians, authorized maximum speed in the roads, visibility distance of stopped, visibility triangle, slope. (Lee, 2005; USDOT, 2007; Multer et al. 2012; Horton, 2009; Huang,2011).

Environment factors: Weather conditions, lighting conditions, time of day and time of year are also effective in accidents (Miranda-Moreno et al., 2012).

Human factors: Driver attributes are a key component to explaining the occurrence of highwayrailway grade crossing collisions. Driver's decision and reaction time, as well as his ability to judge train speed and observe multiple events at once, alcohol, familiarity with crossing, driver demographics (including gender, age, vehicle occupancy, level of skill), human error and unsafe acts are all important factors (USDOT, 2007; Miranda-Moreno et al., 2012).

Crossing factor: There are factors that are related to characteristics of the crossing. Such as presences of gates, traffic signals, and watchmen whistle prohibition, number of collisions, grade crossing maintenance rules (Miranda-Moreno et al., 2009, 2012).

In this context it should be noted that studies of the human factor is very low, while it is one important factor and can be very high impact in safety.

Number of daily trains, highway separation, number of daily trucks, obstacle detection device, and approaching crossing markings significantly affected levels of accident severity at an RGC $(p$-value $=0.0009,0.0008,0.0112,0.0017$, and 0.0003, respectively $) .1$

\section{Countermeasure}

The capacity for current and future grade crossing technologies to reduce the frequency and severity of accidents at highway-railway crossings is reviewed. A number of countermeasures devices have been assessed to determine the reduction of driver accidents with trains. Passive crossings are problematic because of the use of only signage to inform drivers of highway railway grade crossings. The use of stop signs at passive crossings to increase safety has advantages and disadvantages. Street lights at crossings have been shown to reduce nighttime vehicle-train collisions. The conversion of passive crossings to active crossings, by using flashing lights and bells and gates, has been shown to substantially reduce accidents. Upgrading flashing lights and gates to other countermeasures such as photo-enforcement, median barriers, and four quadrant gates have been shown to reduce the frequency and severity of violation behaviors. ITS offers an alternative to conventional warning systems (both active and passive) currently used at grade crossings (Cognitive Ergonomics Research Laboratory Department of Psychology, 2002).

There are several countermeasures that governments use to increase safety at crossing and reduce accident at them: Up to now, there are four types of countermeasure that are in use:

1. Education \& Enforcement: highway-rail grade crossing education and enforcement are options to supplement safety and increase public awareness of the dangers at crossings. There is a need to educate the driving public about their duties and responsibilities at crossings, e.g., via Operation Lifesaver (Office of Railroad Safety, 2010). 
2 Crossing Consolidation/Grade Separation: consolidation and grade separation reduce the risk of a collision to nearly zero because the vehicle and train paths no longer intercept at that location (Horton, 2009).

3. Engineering: Actions that related to design of crossing are in this category e.g. slope, change of angle, improvement of road surface condition, increased view distance (Removal of trees in hazardous locations) (Saccomanno et al., 2007).

Table 2. Various countermeasures and sample references

\begin{tabular}{|c|c|c|c|}
\hline Type & Name & Sample Reference & $\begin{array}{l}\text { Previous } \\
\text { studies }\end{array}$ \\
\hline $\begin{array}{l}\text { Crossing } \\
\text { Elimination }\end{array}$ & Grade Separation/Closure & (Mironer et al. 2000), Gan et al. (2005) & 4 \\
\hline \multirow{6}{*}{$\begin{array}{l}\text { Traffic } \\
\text { Control } \\
\text { Devices } \\
\text { (Passive) }\end{array}$} & Yield Sign & $\begin{array}{l}\text { Agent et al. (1996), Saccomanno et al. } \\
\text { (2007) }\end{array}$ & 7 \\
\hline & Stop Sign & Agent et al. (1996), Gan et al. (2005) & 9 \\
\hline & Stop Ahead Sign & Agent et al. (1996),Park (2007) & 6 \\
\hline & Stop Line Sign & Agent et al. (1996), Park (2007) & 6 \\
\hline & Illumination (Lighting) & ODOT (2006), Saccomanno et al. (2007) & 8 \\
\hline & Pavement Markings & Agent et al. (1996), Gan et al. (2005) & 11 \\
\hline \multirow[b]{2}{*}{ Geometry } & Improving Sight Distance & Agent et al. (1996), ODOT (2006) & 15 \\
\hline & $\begin{array}{l}\text { Improving Pavement } \\
\text { Condition }\end{array}$ & $\begin{array}{l}\text { Hauer and Persaud (1987), Saccomanno et } \\
\text { al. (2007) }\end{array}$ & 7 \\
\hline \multirow{2}{*}{\begin{tabular}{|l} 
Traffic \\
Control \\
Devices
\end{tabular}} & $\begin{array}{l}\text { From Signs to Flashing } \\
\text { Lights }\end{array}$ & (California P.U.C. 1974), ODOT (2006) & 15 \\
\hline & From Signs to 2Q-Gates & (California P.U.C. 1974), (FRA 2001) & 15 \\
\hline \multirow[t]{5}{*}{ (Active) } & $\begin{array}{l}\text { From Flashing Lights to } 2 \mathrm{Q}- \\
\text { Gates }\end{array}$ & (California P.U.C. 1974), (FRA 2001) & 12 \\
\hline & $\begin{array}{c}\text { From } 2 \mathrm{Q} \text {-Gates to } 2 \mathrm{Q} \text { - Gates } \\
\text { with Median Separation }\end{array}$ & (FRA 2001), (Mironer et al. 2000) & 7 \\
\hline & From 2Q-Gates to 4Q- Gates & (Mironer et al. 2000), Park (2007) & 9 \\
\hline & Installing Traffic Signal & Agent et al. (1996),McGee et al. (2003) & 7 \\
\hline & $\begin{array}{l}\text { Elimination of Whistle } \\
\text { Prohibition }\end{array}$ & Rapoza(1999), Saccomanno et al. (2007) & 6 \\
\hline \multirow{2}{*}{ Enforcement } & Posted Speed Limit & Agent et al. (1996), Park (2007) & 6 \\
\hline & Photo/Video Enforcement & McKeever(1998),Caird et al. (2002) & 7 \\
\hline
\end{tabular}

4. Warning systems: Grade crossing protection has been characterized as being passive or active:

a) Passive: Static warning devices that warn the driver of a grade crossing or keep automobiles out of the track way whether or not an train is present, e.g., signs and delineation, Median Separation/Traffic Channelization Devices, 2- Quadrant Gate, Pavement Markings, Alternating passing lanes or four-lane sections at key locations, Restrict or eliminate turning maneuvers, Improve visibility of intersection by providing lighting, Enhanced delineation of sharp curves (Federal Railroad Administration, 2009; Yeh and Multer, 2008)

Active: Warning devices that change states and restrict movement when a train 
approaches, e.g., crossing gates and traffic signals, Active Warning Sign, Flashing Light, and Audible Warning Systems. Although it is the common definition of active grade crossing protection, such systems are essentially proactive; they operate independent of driver's actions or the presence of automobiles (Federal Railroad Administration, 2009; Saccomanno et al., 2007; Ogden, 2007). Table 2 provides the various countermeasures and sample references that noted it.

\section{Conclusion}

In this paper, three basic steps in safety management are discussed. These three steps, network screening for hotspot sites identification, characterization and identification of site factors and selection countermeasure is performed. In review of network screening method can be noted that EB method is the best and common method. It should be noted that in this study, all studies on the railway network screening is investigated. This paper is focused highway-railway crossing that is a hotspot site. In discussion of factors of highway-railway crossing, those studies of the human factor that is more important in safety, is very low and can in future pay more attention to it. In countermeasure field and it is mentioned in the studies reviewed, active countermeasure is most effective and for future studies various countermeasures can be combined and its impact is examined.

\section{References}

Bahar, G., Masliah, M., Philp, C., Shen, K., Park, P., Bhim, R., 2007. Development of a Traffic Safety Management System: High Proportion Screening Tool: Selection of a High Proportion Testing Tool, State of Utah, US Department of Transportation, Interim Report.

Bolduc, D., Bonin, S., 1995. Bayesian analysis of road accidents: accounting for deterministicheterogeneity. In: Proceedings of the Canadian Multidisciplinary Road Safety Conference IX, Montreal, Canada.

Brose, C.A., 2001. Geographic Information Systems for Spatial Analysis of Traffic Collision Locations in La Crosse.Saint Mary's University of Minnesota, Wisconsin.City of Saskatoon, 2009.Traffic Characteristics Report.

Cheng, W.,Washington, S., 2005. Experimental evaluation of hotspot identification methods. Accident Analysis and Prevention 37, 870-881.

Canadian road/railway grade crossing detailed safety assessment field guide, 2005. Transport Canada. Cheng, W., Washington, S., 2008.New Criteria for Evaluating Methods of Identifying Hot Spots.Transportation Research Record, 2083. TRB, National Research Council, Washington, DC, pp. $76-85$.

Cognitive Ergonomics Research Laboratory Department of Psychology, University of Calgary, 2002. A human factors analysis of highway-railway grade crossing accidents in Canada. Transportation Development Centre Transport Canada.

Elvik, R., 2007. State-of-the-Art Approaches to Road Accident Black Spot Management and Safety Analysis of Road Networks.Report 883. Institute of Transport Economics, Oslo. 
Elvik, R., 2008a. Comparative Analysis of Techniques for Identifying Hazardous Road Locations.Transportation Research Record, 2083. TRB, National Research Council, Washington, DC, pp. 72-75.

Federal Railroad Administration, 2009. Highway-Rail Grade Crossing Guidelines for High-Speed Passenger Rail.U.S. Department of Transportation.

Hauer, E., 2004. Statistical Road Safety Modeling.Transportation Research Record, 1897. TRB, National Research Council, Washington, DC, pp. 81-87.

Hauer, E., Allery, B.K., Kononov, J., Griffith, M.S., 2002. Screening the road Network for Sites with Promise.Transportation Research Record, 1784. TRB, National Research Council, Washington, DC, pp. 27-32.

Hauer, E., Allery, B.K., Kononov, J., Griffith, M.S., 2004. How Best to Rank Sites with Promise. Transportation Research Record, 1897. TRB, National Research Council, Washington, DC, pp. $48-54$.

Horton, S., 2009. Success factors in the reduction of highway-rail grade crossing incidents.Volpe national transportation systems center.

Huang, B., 2011. Integrating Pavement Engineering and Road Geometric Factors into Traffic Safety Management for High Speed Facilities.The University of Tennessee.

Kononov, J., 2002. Identifying Locations with Potential for Accident Reductions: Use Of Direct Diagnostics and Pattern Recognition Methodologies.Transportation Research Record, 1784. TRB, National Research Council, Washington, DC, pp. 153-158.

Lyon, C., Gotts, B., Wong, W.K.F., Persaud, B., 2007. Comparison of Alternative Methods for Identifying Sites with High Proportion of Specific Accident Types.Transportation Research Record, 2019. TRB, National Research Council, Washington, DC, pp. 212-218.

Lyon, C., Persaud, B., 2008. Safety Effects of Targeted Program to Improve Skid Resistance.Transportation Research Record, 2068. TRB, National Research Council, Washington, DC, pp. 135-140.

Hauer, E., Persaud, B.N., 1984. Problem of identifying hazardous locations using accident data.Transport. Res. Rec. 975, 36-43.

Hauer, E., NG, J.C.N., Lovell, J., 1988. Estimation of safety at signalized intersections.Transport. Res. Rec. 1185, 48-61.

Hauer, E., 1997. Observational Before-After Studies in Road Safety.Pergamon, Tarrytown, NY. Higle, J.L., Witkowski, J.M., 1988. Bayesian identification of hazardous locations.Transport. Res. Rec. $1185,24-36$.

Higle, J.L., Hecht, M.B., 1989. A comparison of techniques for the identification of hazardous locations.Transport. Res. Rec. 1238, 10-19.

Kelton, W.D., Sadowski, R.P., Sturrock, D.T., 2003. Simulation with Arena. The McGraw-Hill Companies, Inc., NY.

Kononov, J., 2002. Identifying locations with potential for accident reductions: use of direct diagnostics and pattern recognition methodologies. In: Transportation Research Record: Journal of the Transportation Research Board, No. 1784. TRB, National Research Council, Washington, DC, pp. $153-158$.

Kononov, J., Allery, B.K., 2004. Explicit consideration of safety in transportation planning and project scoping. In: Transportation Research Record: Journal of the Transportation Research Board, No. 1897. TRB, National Research Council, Washington, DC, pp. 116-125.

Kononov, J., Janson, B.N., 2002. Diagnostic methodology for the detection of safety problems at intersections. In: Transportation Research Record: Journal of the Transportation Research Board, No. 1784. TRB, National Research Council, Washington, DC, pp. 51-56.

Kononov, J., Allery, B., 2003. Level of service of safety: conceptual blueprint and analytical framework. In: Transportation Research Record: Journal of the Transportation Research Board, No. 1840. TRB, National Research Council, Washington, DC, pp. 57-66.

Masliah, M., Bahar, G., 2006.Using basic collision data to manage road safety. In: Annual Conference of the Transportation Association of Canada, Charlottetown, PEI.

Masliah, M., Bahar, G., Clayton, R., Hall, R., 2006.Managing road using basic crash data. In: Traffic Records Forum Association of Traffic Safety Information Professionals, (ATSIP). 
Mollet, C.J., 2004. Developing a traffic safety improvement program: a review and comparison of different screening network approaches. In: Presented at Canadian Multidisciplinary Road Safety Conference XIV, Ottawa, Ontario.

Maher, M.J., Mountain, L.J., 1988. The identification of accident blackspots: a comparison of current methods. Accident Anal. Prevent. 20 (2), 143-151.

Multer, J., Raslear, Th., Yeh, M., 2012. Evaluating the Impact of Grade Crossing Safety Factors through Signal Detection Theory.Proceedings of the human factors and ergonomics society 56th annual meeting.

Miranda-Moreno, F., Fu, L., Ukkusuri, S., Lord, L., 2009. How to Incorporate Accident Severity and Vehicle Occupancy into the Hot Spot Identification Process? Journal of the Transportation Research Board, No. 2102, Transportation Research Board of the National Academies, Washington, D.C., 2009, pp. 53-60.

Monsere, C., Todd, J., Dixon, K., Zheng, J., Van Schalkwyk, I., 2011. Assessment of Statewide Intersection Safety Performance, Final Report, FHWA-OR-RD-18.Oregon Department of Transportation, Federal Highway Administration.

Montella, A., 2010. A comparative analysis of hotspot identification methods. Accident Analysis and Prevention 42, 571-581.

Miranda-Moreno, F., Fu, L.,Eluru, N.,Bagheri, M., 2012. A latent class modeling approach for identifying vehicle driver injury severity factors at highway-railway crossings. Accident Analysis and Prevention.

Office of Railroad Safety, 2010. Railroad Trespassing, Vandalism, and Highway-Rail Grade Crossing Warning Device Violation Prevention Strategies. U.S. Department of Transportation.

Ogden, B., 2007. Railroad-Highway Grade Crossing Handbook. Washington: Institute of Transportation Engineers.

Park, P., Parisien, J., Sahaji, R., Cozier, C., 2011. Development of geographic information system to identify potential high collision locations in Saskatoon. Saskatchewan Government Insurance, Interim Report.

Persaud, B., 2001. Statistical Methods in Highway Safety Analysis.NCHRP Synthesis 295.Transportation Research Board, Washington, DC.

Persaud, B., Lyon, C., Nguyen, T., 1999.Empirical Bayes Procedure for Ranking Sites for Safety Investigation by Potential for Improvement.Transportation Research Record, 1665. TRB, National Research Council, Washington, DC, pp. 7-12.

Persaud, B.N., 1999. Empirical Bayes procedure for ranking sites for safety investigation by potential for safety improvement.Transport. Res. Rec. 1665, 7-12.

PIARC, World Road Association, Technical Committee on Road Safety C13, 2004.

TAC, Transportation Association of Canada, 2004. The Canadian Guide to In-Service Road Safety Reviews. Ottawa.

Sayed, T., Navin, F., Abdelwahab, W., 1997. A countermeasure based approach for identifying and treating accident prone locations. Canadian Journal of Civil Engineering 24, 683-691.

Saccomanno, F.F., Fu, L., Park, P., 2007. Decision support tool for prioritizing safety improvement programs at high-risk grade crossings. Department of Civil and Environmental Engineering university of Waterloo.

Saccomanno, F.F., Park, P., Fu, L., 2007. Estimating countermeasure effects for reducing collisions at highway-railway grade crossings. Accident Analysis and Prevention 39 (2007) 406-416.

Yeh, M., Multer, J., 2008. Driver behavior at highway-railroad grade crossings: A literature review from 1990-2006. U.S. Department of Transportation. 